\title{
Anastomotic recurrence after 1/3-year rectal neoplasm operated with preservation of the anal sphincter
}

\section{Recidiva anastomotică după neoplasm rectal 1/3 medie operat cu conservarea sfinterului anal}

Daniela Aurora PEŞU ${ }^{1}$, Radu Virgil COSTEA ${ }^{1,2}$, Cristian Constantin POPA ${ }^{1,2}$, Nicoleta Aurelia SANDA ${ }^{1}$, Andreea ILIEŞIU ${ }^{2,3}$, Ştefan Ilie NEAGU ${ }^{1,2,4}$

${ }^{1}$ Secţia de Chirurgie Generală II, Spitalul Universitar de Urgenţă, Bucureşti, România ${ }^{2} U M F$ „Carol Davila“, Bucureşti, România

${ }^{3}$ Secţia de Anatomie Patologică, Spitalul Universitar de Urgenţă, Bucureşti, România ${ }^{4}$ Academia Oamenilor de Ştiinţă din România

\begin{abstract}
The quality of surgery, the limits of resection, the total excretion of "mesorectum", mechanical or manual anastomosis and pre-and postoperative oncologic treatment of rectal cancer, all these, may influence the incidence of local recurrence.

We have analyzed the case of a 62-year old patient with rectal bleeding, diarrhea, and rectal tenesmus. The colonoscopy revealed a rectal tumor located at $10 \mathrm{~cm}$ from anal-rectal limit. A biopsy was taken from the tumor: moderately differentiated adenocarcinoma. CEA and CA19.9 tumor markers were found within normal limits. There was performed rectal resection with end-to-end colonic - rectal anastomosis with Stapler 32. Postoperatively, pathological examination: rectal adenocarcinoma NOS with low degree of malignancy G2 - moderately differentiated, diffuse infiltration to the musculature, without metastasis in regional nodes (only identified 5), completely excised surgically - it was classified as pT2pNo (G2) stage. Postoperatively, the patient did not perform oncology treatment.

Colonoscopy which was performed 1 year after surgery, revealed a bleeding tumor located at the anastomosis level. Biopsies were taken from the anastomosis tumor. The result confirms the local recurrence of invasive adenocarcinoma. Milles rectum amputation is decided and practiced. Postoperatively the patient performs oncological treatment.

Preoperative staging is an important factor in determining the indication of radiotherapy.
\end{abstract}

Keywords: anastomosis recurrence, excision of mesorectum, radiotherapy 


\begin{abstract}
REZUMAT
Calitatea actului chirurgical, limitele de rezecție, excizia totală a "mezorectului", anastomoza mecanică sau manuală şi tratamentul oncologic pre-şi postoperator al cancerului rectal pot influența incidența recidivei locale.

Am analizat cazul unui pacient în vârstă de 62 de ani, cu rectoragii, diaree şi tenesme rectale. Colonoscopia efectuată evidențiază o tumoră rectală situată la $10 \mathrm{~cm}$ de $O A$, din care s-a prelevat biopsie: adenocarcinom moderat diferențiat. Markerii tumorali CEA şi CA19.9 au fost găsiți în limite normale S-a practicat rezecție anterioară de rect cu colorectoanastomoză termino-terminală cu Stappler 32, visceroliză, apendicectomie. Postoperator - examenul histopatologic: adenocarcinom rectal NOS cu grad scăzut de malignitate G2 - moderat diferențiat, infiltrativ difuz până la nivelul muscularei, fără metastaze la nivelul limfoganglionilor locoregionali (identificați doar 5), complet excizat chirurgical - stadiuI pT2pNo(G2). Postoperator, pacientul nu a efectuat tratament oncologic.

La colonoscopia efectuată la 1 an de la intervenția chirurgicală, se descoperă formațiune tumorală sângerândă burjonată, situată la nivelul anastomozei, din care se prelevează biopsii. Rezultatul confirmă recidiva locală de adenocarcinom invaziv. Se decide şi se practică amputație de rect tip Milles. Postoperator, pacientul efectuează tratament oncologic.

Stadializarea preoperatorie reprezintă un factor important în stabilirea indicației de radioterapie.
\end{abstract}

Cuvinte cheie: recidivă anastomotică, excizia mezorectului, radioterapie

\section{INTRODUCERE}

Recidivele locale după cancerul de rect sunt reprezentate de recurenţele limitate la rect, pelvis sau organele adiacente, putând fi anastomotice sau în vecinătatea fostei tumori şi limfonodulare pelvine.

Recurenţele locale apar în 18-20 \% dintre cazuri în primele 18- 24 luni postoperator, fiind favorizate de mai mulţi factori: vârsta avansată a pacienţilor, stadiul avansat al tumorii, neoplasme din celule nediferenţiate, cancere de rect complicate (ocluzie, perforaţie), gestul chirurgical şi tehnicile de manipulare tumorală neadecvată, dehiscenţă anastomotică - fistule parţiale, amploarea transfuzatelor necesare, obezitate morbidă $(1,2)$.

Calitatea actului chirurgical, limitele de rezecţie, excizia totală a "mezorectului“, anastomoza mecanică sau manuală şi tratamentul oncologic pre- şi postoperator al cancerului rectal pot influenţa incidenţa recidivei locale.

Un factor important în tratamentul pacienţilor cu cancer rectal este reprezentat de marginile laterale de rezecţie şi nu numai de marginile distală sau proximală libere $(3,4,5)$.

Tratamentul cancerului rectal a beneficiat, în primul rând, de îmbunătăţirea calităţii vieţii prin conservarea aparatului sfincterian şi coborârea limitelor de rezecţie, chirurgia oncologică vizând tehnici de rezecţie în condiţii de radicalitate oncologică (6).

De aceea, recurenţa locală prezintă o variaţie diferită de funcţii: de calitatea actului chirurgical, de stadializarea tumorii, de vârsta şi comorbidităţile bolnavului, de invazia ganglionilor limfatici locoregionali, de invazia perivasculară.

În 1982, Heald RJ a descris faptul că excizia totală a mezorectului poate reduce recurenţa locală sub 5\% (7). Marvin Corman arată că „operaţia pentru tumori rectale, descrisă de Heald, este, în esenţă, aceeaşi cu cea practicată de mai mulţi ani de cei mai mulţi chirurgi“ (8).

Scopul lucrării de faţă este de a evidenţia faptul că acurateţea intervenţiei chirurgicale -excizia totală a mezorectului, radioterapia preoperatorie sau postoperatorie, chimioterapia pot scădea riscul recidivei locale în cancerul rectal operat.

Calitatea vieţii bolnavului cu recidivă locală este afectată, pacientul trecând prin două intervenţii dificile, după un tratament oncologic susţinut frecvent, de la o operaţie care îi păstra aparatul sfincterian la o intervenţie care presupune şi extirparea în totalitate a sfincterului anal şi colostoma.

Colostoma reprezenta pentru bolnav o invaliditate, în privinţa imaginii corporeale, a stimei de sine, producând uneori un impact negativ asupra psihicului, pacientul devenind retras şi anxios şi necesitând consiliere psihologică şi, uneori, tratament psihiatric. Paradoxal, în cazul de faţă, pacientul deşi are 65 de ani, fiind purtător de colostoma, duce un regim de viaţa normal, făcând sport, având activităţi sociale extinse şi un optimism debordat. 


\section{PREZENTAREA CAZULUI}

Am analizat cazul unui pacient în vârstă de 62 de ani, din mediul urban, fără comorbidităţi, internat în Clinica de Chirurgie II a Spitalului Universitar de Urgenţă prin cronici în ianuarie 2016, pentru: rectoragii, diaree şi tenesme rectale.La tuşeul rectal se decela o formaţiune tumorală circumferenţială, uşor stenozantă I. Colonoscopia efectuată evidenţiază o tumoră rectală situată la $10 \mathrm{~cm}$ de $O A$, din care s-a prelevat biopsie. Rezultatul histopatologic: adenocarcinom moderat diferenţiat. Din analizele de laborator, markerii tumorali CEA şi CA19.9 erau în limite normale, proteine totale: $7,07 \mathrm{~g} / \mathrm{dl}, \mathrm{Hgb}: 15 \mathrm{~g} / \mathrm{dl}$. Explorările radiologice nu evidenţiază prezenţa metastazelor.

S-a intervenit chirurgical şi s-a practicat rezecţie anterioară de rect, cu colorectoanastomoză termino-terminală cu Stappler 32, visceroliză, apendicectomie. Evoluţia postoperatorie este simplă. Pacientul se externează vindecat chirurgical la 9 zile postoperator. Examenul histopatologic al piesei de rezecţie descrie o formaţiune tumorală ulcero-vegetantă şi infiltrativă $3 / 3 / 0,5 \mathrm{~cm}$, cu zone de ulceraţie superficială ce infiltrează seroasa: adenocarcinom rectal NOS cu grad scăzut de malignitate G2 - moderat diferenţiat, infiltrativ difuz până la nivelul muscularei, fără metastaze la nivelul limfoganglionilor locoregionali (identificaţi doar 5), complet excizat chirurgical - stadiul pT2pNo (G2). Postoperator, pacientul nu a efectuat tratament oncologic.

La 6 luni după excizia tumorii rectale, pacientului i se descoperă tomografic o singură formaţiune tumorală la nivel LIS pulmonar, pentru care se practică rezecţie atipic subsegmentară segment 8 stâng.
Rezultatul anatomopatologic arată tuberculom, pacientul având o evoluţie postoperatorie simplă.

Pacientul efectuează controale la 3, 6 şi 9 luni postoperator, fiind asimptomatic. La colonoscopia efectuată la 1 an de la intervenţia chirurgicală, se descoperă o formaţiune tumorală sângerândă burjonată, situată la nivelul anastomozei, din care se prelevează biopsii. Rezultatul confirmă recidiva locală de adenocarcinom invaziv.

Se decide şi se practică amputaţie de rect tip Milles. Postoperator, pacientul a dezvoltat enterocolită cu Clostridium difficile, motiv pentru care s-a instituit tratament specific, evoluţia fiind favorabilă.

Rezultatul anatomopatologic descrie piesa de rezecţie de $30 \mathrm{~cm}$ cu recidivă tumorală de adenocarcinom la nivelul anastomozei convenţional NOS cu grad scăzut de malignitate - $G 2$ şi un polip sigmoidian tubulo-vilos cu leziuni de neoplazie intraepiteliala de grad înalt. Nu s-au descris ganglioni.

Postoperator, pacientul efectuează tratament oncologic: radioterapie loco-regională $50,4 \mathrm{~Gy} / 28$ şedinţe, concomitent cu capecitabină $825 \mathrm{mg} / \mathrm{mp}$ BID, cu toleranţă relativ bună.

Ultimul RMN efectuat nu evidenţiază modificări, respectiv metastaze locoregionale sau la distanţă (hepatice, pulmonare). Pacientul revine constant la control la 3 luni.

\section{DISCUTุII}

Cazul prezentat ridică câteva aspecte legate, în primul rând, de importanţa tratamentului oncologic pre-şi postoperator. În acest sens, radioterapia preoperatorie ar fi putut elimina posibilitatea recidivei locale şi preveni astfel reintervenţia?
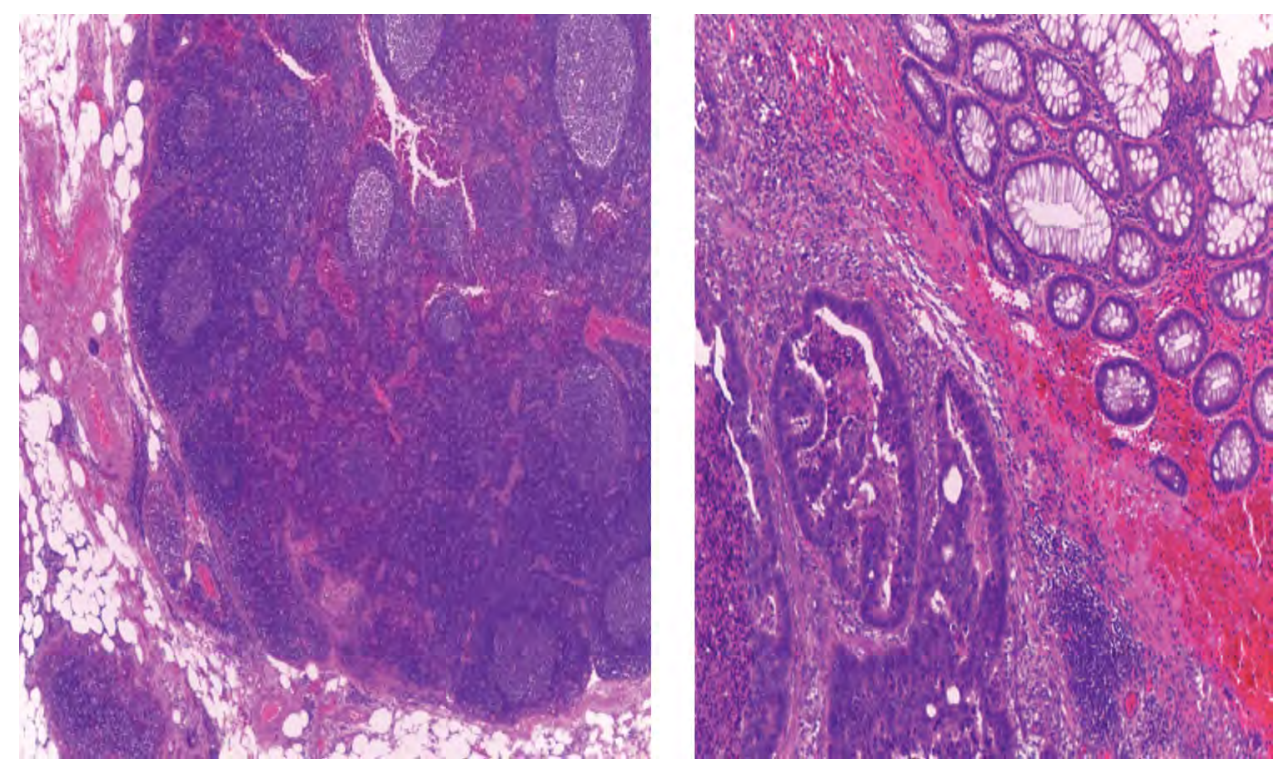

FIGURILE 1, 2. Imagini de microscopie cu tumora rectală recidivată a cazului expus 
Stadializarea postoperatorie nu a indicat efectuarea radioterapiei. Avantajele radioterapiei preoperatorii sunt incontestabile: scade incidenţa recidivei locale, creşte rata rezecabilităţii prin reducerea volumului tumoral (down staging), scade posibilitatea diseminării intraoperatorii a neoplaziei, sterilizează micrometastazele / adenopatiile regionale, creşte posibilitatea practicării intervenţiilor de rezecţie cu conservarea sfincterului anal. Efectele negative ale radioterapiei sunt, de asemenea, binecunoscute şi importante: sindrom aderenţial, microangiopatia radică digestivă (rectita, colita, enterita radică cu evoluţie posibilă spre fistulizare) sau urinară (vezică mică radică), cu afectarea procesului de cicatrizare locală şi risc crescut de fistulizare în cazul efectuării ulterioare a unor anastomoze digestive. Stadializarea preoperatorie reprezintă un factor important în stabilirea indicaţiei de radioterapie. Alt factor important este radiosensibilitatea tumorii, care poate fi determinată asfel încât indicaţia de radioterapie să fie individualizată.
Reanalizând rezultatul histopatologic, am constatat că acesta specifică prezenţa interesării seroasei de către procesul neoplazic, fapt care ar încadra tumora în stadiul T3 şi nu T2, cum apare în aprecierea anatomopatologului. De asemenea, identificarea doar a 5 ganglioni în piesa de rezecţie pune sub semnul întrebării amploarea exerezei limfatice adiacente tumorii. Este un caz cu eferenţă limfatică săracă sau exereza noastră a fost ineficientă? Având în vedere aceste considerente, cât şi producerea recidivei anastomotice, putem considera că s-a realizat o substadializare iniţială, considerându-se cazul în stadiul I (T2NOG2M0), ceea ce a privat bolnavul de radioterapia postoperatorie.

American Society of Oncology (ASCO), American Society of Colon Rectal Surgeons (ASCRS), European Society for Medical Oncoloy (ESMO), Association of Coloproctology of Great Britain and Ireland (ACPGBI), National Comprehensive Cancer Network (NCCN) au conceput recomandările actuale cu privire la controlul efectuat de către pacienţii operaţi de tumori rectale, toate acestea fiind sistematizate în tabelul $1(9,10,11,12,13)$.

TABELUL 1. Recomandările actuale cu privire la controlul efectuat de către pacienţii operaţi de tumori rectale

\begin{tabular}{|c|c|c|c|c|c|}
\hline Guideline & MH\&PE & CEA & $\begin{array}{l}\text { Abdominal } \\
\text { imaging }\end{array}$ & $\begin{array}{l}\text { Chest } \\
\text { imaging }\end{array}$ & Colonoscopy \\
\hline $\operatorname{ASCO}(9)$ & $\begin{array}{l}\text { Every } 3-6 \text { months } \\
\text { for } 5 \text { years }\end{array}$ & $\begin{array}{l}\text { Every } 3-6 \text { months } \\
\text { for } 5 \text { years }\end{array}$ & $\begin{array}{l}\text { CT abdomen and } \\
\text { pelvis annually for } 3 \\
\text { years, for high risk } \\
\text { pacients every } 6-12 \\
\text { months for } 3 \text { years } \\
\text { and then annnualy } \\
\text { for } 2 \text { years }\end{array}$ & $\begin{array}{l}\text { CT of Chest annually } \\
\text { for } 3 \text { years, for high } \\
\text { risk pa ts every } \\
6-12 \text { months for } 3 \\
\text { years }\end{array}$ & $\begin{array}{l}\text { Colonoscopy at } 1 \text { year, } \\
\text { subsequently according indings } \\
\text { and every } 5 \text { years if normal } \\
\text { Rectosigmoidoscopy every } 6 \\
\text { months for } 5 \text { years în rectal } \\
\text { cancer not irradiated }\end{array}$ \\
\hline ASCRS (8) & $\begin{array}{l}\text { Every } 3-6 \text { months } \\
\text { for } 2 \text { years, then } \\
\text { every } 6 \text { months for } \\
3 \text { years }\end{array}$ & $\begin{array}{l}\text { Every } 3-6 \text { months } \\
\text { for } 2 \text { years, then } \\
\text { every } 6 \text { months for } \\
3 \text { years }\end{array}$ & $\begin{array}{l}\mathrm{CT} \text { of abdomen } \\
\text { within } 2 \text { years }\end{array}$ & $\begin{array}{l}\text { Ct of chest annually } \\
\text { for } 5 \text { years }\end{array}$ & $\begin{array}{l}\text { Rectosigmoidoscopy (+/- ERUS) } \\
\text { very } 6 \text { to } 12 \text { months or every } \\
6 \text { months for } 3 \text { to } 5 \text { years în } \\
\text { high risk pa nfs (lympha } \\
\text { and venous invasion, poorly } \\
\quad \text { eren ? , male sex, distal } \\
\text { lesion, close distal margins, } \\
\text { transanal local excision) }\end{array}$ \\
\hline ESMO (10) & $\begin{array}{l}\text { Every } 6 \text { months for } \\
2 \text { years }\end{array}$ & NR & NR & NR & $\begin{array}{l}\text { Rectosigmoidoscopy every } 6 \\
\text { months for } 2 \text { years; } \\
\text { Colonoscopy every } 5 \text { years }\end{array}$ \\
\hline ACPGBI (11) & $\begin{array}{l}\text { Audit îs } \\
\text { mandatory but not } \\
\text { recommenda } \\
\text { for frequency }\end{array}$ & NR & $\begin{array}{l}\text { CT of abdomen } \\
\text { within } 2 \text { years }\end{array}$ & $\begin{array}{l}\mathrm{CT} \text { of chest within } \\
2 \text { years }\end{array}$ & Colonoscoy every 5 years \\
\hline NCCN (12) & $\begin{array}{l}\text { Every } 3-6 \text { months } \\
\text { for } 2 \text { years, then } \\
\text { every } 6 \text { months for } \\
3 \text { years }\end{array}$ & $\begin{array}{l}\text { Every 3-6 months } \\
\text { for } 2 \text { years, then } \\
\text { every } 6 \text { months for } \\
3 \text { years for T2 or } \\
\text { greater lesions }\end{array}$ & $\begin{array}{l}\text { CT of abdomen and } \\
\text { pelvis annually for } \\
5 \text { years în high risk } \\
\text { pacient(lympha } \\
\text { and venous } \\
\text { invasion, poorly } \\
\text { eren ? ) }\end{array}$ & $\begin{array}{l}\text { CT of chest } \\
\text { annually for } 5 \\
\text { years în high risk } \\
\text { pacients (lympha } \\
\text { and venous } \\
\text { invasion, poorly } \\
\text { eren ? }\end{array}$ & $\begin{array}{l}\text { Colonoscopy at } 1 \text { year, repeat în } 3 \\
\text { years then every } 5 \text { years }\end{array}$ \\
\hline
\end{tabular}


De remarcat este că fiecare societate/asociaţie are diferite moduri de a investiga bolnavul la controalele curente. Instituţiile americane - ASCO, ASCRS şi NCCN - au schema cea mai încărcată în investigaţii (CEA, CT abdomen, pelvis, torace, colonoscopie), în timp ce instituţiile europene recomandă o schemă mai redusă a investigaţiilor fără CEA, iar pentru ESMO şi fără CT. Toate societăţile recomandă însă examenul clinic la 3-6 luni pentru 5 ani şi colonoscopia la 6-12 luni pentru 5 ani. Având în vedere faptul că majoritatea recidivelor şi metastazelor se produc în primii 2 ani postoperator, în această perioadă, controalele se fac mai frecvent la 3 luni, urmând a se face la interval mai mari între 2 şi 5 ani (6-12 luni) şi anual după 5 ani. Intervalul mai scurt este adoptat în cazurile în care riscul de recidivă şi metastazare este mai mare (stadiile II, III, T3, T4, N1, 2, G3, 4 perforaţia tumorii prezentă, invazie limfatică, vasculară, perineurală prezentă). Dintre toate societăţile, ASCO recomandă testarea în primii 2 ani, considerând că recurenţa apare în primii 2-2,5 ani de la excizia tumorii rectale (14).

\section{CONCLUZII}

Scopul controlului postoperator este de a sesiza cât mai curând reluarea evoluţiei bolii, fie prin apariţia metastazelor la distanţă, fie prin recidivă locală, asfel încât să se poată interveni terapeutic, oncologic şi chirurgical cât mai precoce.

Conflict of interest: none declared Financial support: none declared

\section{BIBILIOGRAFIE}

1. Lawes D, Boulos TB. Advances in management of rectal cancer. J.R Soc Med 2002. 95(12):587-590.

2. C Plesca, C Dragomir, Ilie Tighiliu. Cancerul de rect recidivat. Jurnalul de Chirurgie laşi 2007, vol. 3, nr. 3.

3. Enker WE, Thaler HT, Cranor ML, Polyak T. Total mesorectal excision în the operative treatment of carcinoma of the rectum. J Am Coll Surg 1995; 181(4): 335-346.

4. Quirke P, M Dixon F, Durdey P, Williams NS. Local recurrence of rectal adenocarcinoma due to inadequate surgical resection. Histopathological study of lateral tumor spread and surgical excision. Lancet 1986; 8514:996-999.

5. Nagtegaal ID, van de Velde CJ, Marijnen CA, van Krieken JH, Quirke P. Dutch Colorectal Cancer Group; Pathology Review Committee. Low rectal cancer: A call for a change of approach în abdominoperineal resection. Journal of Clinical Oncology 2005; 23(36): 9257-9264.
6. Lili-Gabriela Lozneanu, G Dimofte, Simona Nicolescu, V Boboc, E Tarcoveanu. Recurenţa locală după excizia totală a mezorectului, o problemă de actualitate. Jurnalul de Chirurgie laşi 2011, vol 7. Nr 3.

7. Heald RJ, Husband EM, Ryall RD. The mesorectum în rectal cancer surgery - the clue to pelvic recurrence. Br J Surg 1982; 69(10): 613-616.

8. Marvin L Coman. Colon and Rectal Surgery. Ed. 4 Lippincot - Raven, pub 1998, p. 788.

9. Steele SR, Chang GJ, Hendren S et al. Practice guidelines for the surveillance of patients after curative treatment of colon and rectal cancer. Dis Colon Rectum 2015. 58:713-725.

10. Meyerhardt JA, Mangu PB, Flynn PJ et al. Follow-up care, surveillance protocol, and secondary prevention measures for survivor of colonrectal cancer: American Society of Clinical Oncology clinical practice guideline endorsement. J Clin Oncol 2013. 31:4465-4470.
11. Glimelius B, Oliveira J. Rectal cancer: ESMO clinical reccomendations for diagnosis, treatment and follow-up. Ann Oncol 2009. 20:54-56.

12. Guidelines for the management of colorectal cancer 3rd edition (2007). Available at: http://acpgbi.mixd.co.uk/ content/uploads/2007-CC-ManagementGuidelines.pdf. Accessed February 26, 2015.

13. NCCN clinical practice guidelines în oncology (NCCN guidelines). Rectal Cancer. Version 2. 2015 Available at:http:// www.nccn.org/professionals/physician_gls/ pdf/rectal.pdf. Accessed February 26, 2015.

14. Giovanni Maria Romano, Francesco Bianco. Multimodal Treatment of Recurrent Pelvic Colorectal Cancer 2015: Follow-up Strategy after Primary and Early Diagnosis, cap 1.7 (pp. 7-9), Springer, 2016. 